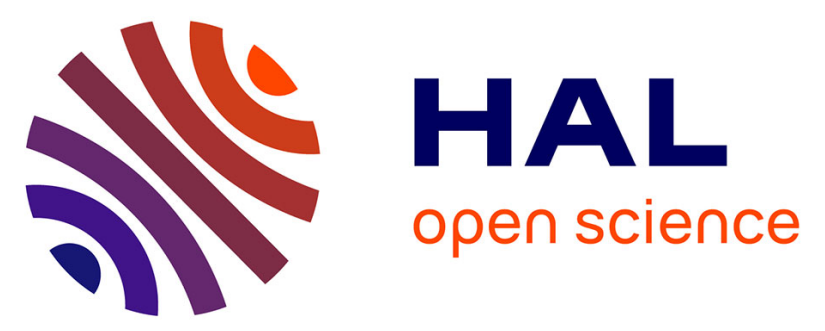

\title{
Beetroot Juice Does Not Enhance Supramaximal Intermittent Exercise Performance in Elite Endurance Athletes.
}

Medhi Pawlak Chaouch, Julien Boissiere, Desire Munyaneza, Francois-Xavier

Gamelin, Gregory Cuvelier, Serge Berthoin, Julien Aucouturier

\section{To cite this version:}

Medhi Pawlak Chaouch, Julien Boissiere, Desire Munyaneza, Francois-Xavier Gamelin, Gregory Cuvelier, et al.. Beetroot Juice Does Not Enhance Supramaximal Intermittent Exercise Performance in Elite Endurance Athletes.. Journal of the American College of Nutrition, 2019, Journal of the American College of Nutrition, pp.1-10. 10.1080/07315724.2019.1601601 . hal-02375504

\section{HAL Id: hal-02375504 https: / hal.univ-lille.fr/hal-02375504}

Submitted on 22 Nov 2019

HAL is a multi-disciplinary open access archive for the deposit and dissemination of scientific research documents, whether they are published or not. The documents may come from teaching and research institutions in France or abroad, or from public or private research centers.
L'archive ouverte pluridisciplinaire HAL, est destinée au dépôt et à la diffusion de documents scientifiques de niveau recherche, publiés ou non, émanant des établissements d'enseignement et de recherche français ou étrangers, des laboratoires publics ou privés. 
Pawlak-Chaouch M, Boissière J, Munyaneza D, Gamelin FX, Cuvelier G, Berthoin S, Aucouturier J. Beetroot Juice Does Not Enhance Supramaximal Intermittent Exercise Performance in Elite Endurance Athletes. J Am Coll Nutr. 2019 Nov-Dec;38(8):729-738. doi: $10.1080 / 07315724.2019 .1601601$

Beetroot juice does not enhance supramaximal intermittent exercise performance in elite endurance athletes

Mehdi Pawlak-Chaouch ${ }^{1}$, Julien Boissière ${ }^{1}$, Désiré Munyaneza ${ }^{1}$, François-Xavier Gamelin ${ }^{1}$, Grégory Cuvelier ${ }^{2}$, Serge Berthoin ${ }^{1}$, Julien Aucouturier ${ }^{1}$

\section{Authors Affiliations:}

1 Univ. Lille, Univ. Artois, Univ. Littoral Côte d'Opale, EA 7369 - URePSSS Pluridisciplinary Research Unit « Sport, Health and Society », F-59000 Lille, France.

${ }^{2}$ Laboratory of Exercise and Movement, Provincial School of Hainaut (HEPH)-Condorcet, Tournai, Belgium.

\section{Corresponding author:}

Mehdi PAWLAK-CHAOUCH, PhD

Pluridisciplinary Research Unit « Sport, Health and Society »

(URePSSS) - EA7369

Lille University 
Eurasport

413 Avenue Eugène Avinée

59120 LOOS

Tel: $+33(0) 603684965$

E-mail : pawlak.mehdi@orange.fr; medhi.pawlak-chaouch@univ-lille.fr

\section{ABSTRACT}

Objective: Nitrate $\left(\mathrm{NO}_{3}^{-}\right)$-rich beetroot juice $(\mathrm{BR})$ is recognized as an ergogenic supplementation that improves exercise tolerance during submaximal to maximal intensity exercise in recreational and competitive athletes. A recent study has investigated the effectiveness of BR on exercise performance during supramaximal intensity intermittent exercise (SIE) in Olympic-level track cyclists, but studies conducted in elite endurance athletes are scarce. The present study aimed to determine whether BR supplementation enhances the tolerance to SIE in elite endurance athletes.

Methods: Eleven elite endurance athletes (age: 21.7 \pm 3.7 years, maximal oxygen uptake $\left.\left(\dot{\mathrm{VO}}_{2 \max }\right): 71.1 \pm 5.2 \mathrm{~mL} \cdot \mathrm{kg}^{-1} \cdot \mathrm{min}^{-1}\right)$ performed a SIE test until exhaustion following either a 3-day BR supplementation (340 mg/day) or a placebo (PL) supplementation ( $<2,5 \mathrm{mg} /$ day) in a randomized, single blind, placebo-controlled and crossover study. The exercise test consisted of 15 -s cycling exercise bouts at $170 \%$ of the maximal aerobic power interspersed with 30-s passive recovery periods. Gas exchange was measured during SIE tests as local muscle $\mathrm{O}_{2}$ delivery and extraction were assessed by near infrared spectroscopy.

Results: The number of repetitions completed was not significantly different between BR (13.9 \pm 4.0 reps) and PL conditions (14.2 \pm 4.5 reps). BR supplementation did not affect oxygen uptake $\left(\mathrm{V}_{2}\right)$ during SIE tests $\left(\mathrm{BR}: 3378.5 \pm 681.8 \mathrm{~mL} \cdot \mathrm{min}^{-1}\right.$, PL: $\left.3466.1 \pm 505.3 \mathrm{~mL} \cdot \mathrm{min}^{-1}\right)$. No significant change in the areas under curves was found for local muscle total hemoglobin 
(BR: $6816.9 \pm 1463.1$ arbitrary units (a.u.), PL: $6771.5 \pm 3004.5$ a.u.) and deoxygenated hemoglobin (BR: $6619.7 \pm 875.8$ a.u., PL: $6332.7 \pm 1336.8$ a.u.) during time-matched work+recovery periods from SIE tests following BR supplementation.

Conclusion: BR supplementation does not enhance the tolerance to supramaximal intensity intermittent exercise in elite endurance athletes and does affect neither $\dot{\mathrm{V}} \mathrm{O}_{2}$ nor local muscle $\mathrm{O}_{2}$ delivery and extraction.

Keywords: dietary nitrate; high aerobic fitness; exercise tolerance; endurance athletes; intermittent exercise

\begin{abstract}
Abbreviations: AUC: Area Under the Curve; ATP: adenosine triphosphate; BR: beetroot juice; DBP: diastolic blood pressure; $\mathrm{Hb}$ : hemoglobin; $\mathrm{HbO}_{2}$ : muscle oxygenated hemoglobin; HHb: muscle deoxygenated hemoglobin; NIRS: near infrared spectroscopy; $\mathrm{Mb}$ : myoglobin; $\mathrm{NO}$ : nitric oxide; $\mathrm{NO}_{3}^{-*}$ : nitrate; $\mathrm{NO}_{2}^{-}$: nitrite; $\mathrm{NO}_{\mathrm{x}}$ : nitrate+nitrite; $\mathrm{PL}$ : placebo; RER: respiratory exchange ratio; SBP: systolic blood pressure; SIE: supramaximal intensity intermittent exercise; THb: muscle total hemoglobin; TM: time-matched data; $\dot{V E}$ : minute ventilation; $\dot{\mathrm{V}} \mathrm{CO}_{2}$ : carbon dioxide output; $\dot{\mathrm{V}} \mathrm{O}_{2}$ : oxygen uptake; $\dot{\mathrm{V}} \mathrm{O}_{2 \max }$ : maximal oxygen uptake.
\end{abstract}




\section{Introduction}

Nitric oxide (NO) is a ubiquitous signaling molecule that possesses the ability to improve vascular function, mitochondrial efficiency and respiration, glucose homeostasis and muscle contractility (1). NO is enzymatically produced by the nitric oxide synthase (NOS) that is dependent on L-arginine and oxygen availability, and thus becomes limited in hypoxia (2). However, a relevant alternative source of NO has emerged through the consumption of nitrate $\left(\mathrm{NO}_{3}{ }^{-}\right)$-rich vegetables such as lettuce, spinach and beetroot (3). Dietary $\mathrm{NO}_{3}{ }^{-}$are absorbed from the small intestine, and after an entero-salivary recirculation and concentration into the saliva, are converted into nitrite $\left(\mathrm{NO}_{2}^{-}\right)$by oral $\mathrm{NO}_{3}{ }^{-}$reductase bacteria (3). The swallowed salivary $\mathrm{NO}_{2}^{-}$are either reduced to $\mathrm{NO}$ and other nitrogen species in the acidic stomach or absorbed from the intestine, and thus increase endogenous circulating NO pool (3).

The consumption of dietary $\mathrm{NO}_{3}{ }^{-}$is recognized as a nutritional aid to improve tolerance to submaximal to maximal intensity exercise (4). The increase in exercise tolerance has been mostly attributed to decreased ATP cost of muscle contraction (5), and improved oxidative efficiency (6). Some studies reported that $\mathrm{NO}_{3}{ }^{-}$-rich beetroot juice (BR) supplementation did not change any indices of mitochondrial coupling and respiratory efficiency (7) and did not alter in vivo muscle oxidative efficiency in recreationally active males (8). In these studies, the authors found decreased whole-body and muscle $\dot{\mathrm{V}} \mathrm{O}_{2}$ during submaximal cycling and isometric handgrip exercise, respectively $(7,8)$. Thus, BR supplementation may act through divergent mechanisms than sodium nitrate (9) by improving skeletal muscle contractile efficiency $(7,10)$ and/or local tissue perfusion $(8,11)$. However, a number of studies did not show any change in exercise performance during time-trial tests following $\mathrm{NO}_{3}{ }^{-}$ supplementation (12-16), particularly in elite endurance athletes. In situations in which muscle $\mathrm{O}_{2}$ supply may be restricted, Shannon et al showed that well-trained individuals can 
also experience benefits from dietary $\mathrm{NO}_{3}{ }^{-}$supplementation during high-intensity exercise (17).

Moreover, mixed findings have especially been reported regarding the effect of $\mathrm{NO}_{3}{ }^{-}$ supplementation on supramaximal intensity exercise (SIE) performance $(12,18-21)$. This type of exercise is known to recruit a high proportion of type II, predominantly glycolytic, muscle fibers (22) that are characterized by lower $\mathrm{O}_{2}$ availability than type I, highly oxidative, muscle fibers (23). As such, the reduction of $\mathrm{NO}_{3}{ }^{-}$to $\mathrm{NO}$ may be enhanced in type II muscles fibers given that it preferentially occurs in both acidic and hypoxic conditions (3). Running time over a single $180 \mathrm{~m}$ sprint was shown to be improved (18), and we also reported improved tolerance to the repetition of supramaximal intensity bouts of exercise $(\geq 170 \%$ power output at $\left.\dot{\mathrm{V}} \mathrm{O}_{2 \text { max }}\right)$ in moderately fit subjects $\left(\dot{\mathrm{V}}_{2 \max }\right.$ between 40 and $\left.55 \mathrm{~mL} \cdot \mathrm{kg}^{-1} \cdot \mathrm{min}^{-1}\right)$ following dietary $\mathrm{NO}_{3}{ }^{-}$supplementation (19). However, in contrast to findings during submaximal intensity exercise, enhanced tolerance to SIE was not related to any decrease in oxygen uptake $\left(\dot{\mathrm{V}}_{2}\right)$ or in anaerobic energy production $(19,20)$. Apart from improving exercise tolerance, we found an increase in local muscle total hemoglobin during SIE after 3-day beetroot juice (BR) supplementation (19). By better maintaining $\mathrm{O}_{2}$ delivery to the working muscle, $\mathrm{NO}_{3}{ }^{-}$ supplementation likely delays the depletion of muscle phosphocreatine ( $\mathrm{PCr}$ ) and the accumulation of adenosine diphosphate (ADP) and phosphate ion (Pi) metabolites (24), and promotes $\mathrm{PCr}$ resynthesis, dependent on oxidative phosphorylation (25). In combination, these effects can attenuate the development of muscle fatigue and contribute to sustain power output between supramaximal intensity exercise bouts. To date, no investigation was assessed local muscle $\mathrm{O}_{2}$ delivery and extraction in elite endurance athletes conducting SIE tests after BR supplementation.

There is mounting evidence suggesting that the level of aerobic fitness of the athletes modulates the effects of $\mathrm{NO}_{3}^{-}$supplementation on performance $(26,27)$. Porcelli et al. 
demonstrated that the magnitude of increase in exercise performance during a 3000-meter running race time trial was inversely correlated to $\dot{\mathrm{V}} \mathrm{O}_{2 \max }$, with no benefit for athletes with $\dot{\mathrm{V}} \mathrm{O}_{2 \max }$ above $60 \mathrm{~mL} \cdot \mathrm{kg}^{-1} \cdot \mathrm{min}^{-1}$. Conversely, most studies that reported enhanced performance were conducted in non-endurance athletes or moderately trained subjects $\left(\dot{\mathrm{V}} \mathrm{O}_{2 \max } \sim 50 \mathrm{~mL} \cdot \mathrm{kg}^{-1} \cdot \mathrm{min}^{-1}\right) \quad(5,19,28-33)$. The reasons for a lower effectiveness are still unclear, but may be related to characteristics of athletes with high $\dot{\mathrm{V}} \mathrm{O}_{2 \max }$, such as already high synthesis of NO through the enzymatic pathway (34), and a high proportion of type I muscle fibers, which are less sensitive to an increase in NO bioavailability than type II muscle fibers (23).

Nevertheless, dietary $\mathrm{NO}_{3}{ }^{-}$supplementation may be of great interest to endurance athletes that will engage in high-intensity training and/or events. Although mean exercise intensity is submaximal in endurance sports, the time spent beyond power output corresponding to $\dot{\mathrm{V}} \mathrm{O}_{2 \max }$ can exceed $15 \%$ of the total race duration in activities such as cycling or triathlon (35). Moreover, the time spent at these supramaximal intensities is distributed into short bouts of exercise across the duration of the event (36). The exercise performance may be impacted by the capacity to maintain efforts in successive high-intensity exercise intervals over a long time period (37). Furthermore, middle-distance athletes (800 to 5000-10 000m), who are also characterized by high $\dot{\mathrm{V}} \mathrm{O}_{2 \max }$, select pacing strategies during running competition events so that they regularly run at speeds well above the $\dot{\mathrm{V}} \mathrm{O}_{2 \max }$ intensity (38). Interval training protocols at supramaximal intensity allow to maximally strain aerobic and anaerobic metabolism (39) and to enhance physiological determinants of exercise performance even in athletes that have already elicited cardiorespiratory adaptations to chronic exercise training $(38,40,41)$.

Our purpose was therefore to determine whether dietary $\mathrm{NO}_{3}^{-}$supplementation enhances tolerance to supramaximal intensity intermittent exercise (SIE) in elite endurance athletes 
having high aerobic fitness $\left(\dot{\mathrm{V}} \mathrm{O}_{2 \max }>65 \mathrm{~mL} \cdot \mathrm{kg}^{-1} \cdot \mathrm{min}^{-1}\right)$. We hypothesized that dietary $\mathrm{NO}_{3}^{-}$ supplementation would increase plasma $\mathrm{NO}_{\mathrm{x}}$ levels without improving tolerance to exercise. 


\section{Material and Methods}

\section{Population}

Subjects' characteristics are presented in Table 1. Subjects were contacted in track and field and triathlon clubs and were all engaged in intense endurance exercise training and competitive running or triathlon. Eleven subjects were initially recruited for the study and two subjects were excluded after completing the preliminary visit because they did not meet the criteria for inclusion $\left(\mathrm{V}_{2 \max }>65 \mathrm{~mL} \cdot \mathrm{kg}^{-1} \cdot \mathrm{min}^{-1}\right)$. Subjects were not taking any nutritional supplement or medication known to affect NO metabolism. All subjects were informed about the study protocol, its potential risks and benefits, and gave written consent to participate in this study. Subjects were concealed to the true aim of study and were told that the purpose of trials was to compare the ergogenic effects of two beverages. The protocol of the study complied with the Declaration of Helsinki and was approved by the Institutional Ethics Committee of the Haute Ecole Provinciale du Hainaut.

\section{- Table 1 here -}

\section{Incremental maximal exercise test}

At least one week before the first experimental visit, subjects performed an incremental exercise test until volitional exhaustion to ensure their eligibility for the study. $\dot{\mathrm{V}} \mathrm{O}_{2 \max }$ and Power Output at $\dot{\mathrm{V}} \mathrm{O}_{2 \max }$ were measured during a graded exercise test until volitional exhaustion performed on a mechanically braked cycle ergometer (894E, MONARK EXERCISE TM, Sweden). The test was initiated at $100 \mathrm{~W}$ for $3 \mathrm{~min}$ and increased by $35 \mathrm{~W}$ increments every $2 \mathrm{~min}$. Subjects were invited to maintain a pedaling frequency of $80 \mathrm{rpm}$ 
and were strongly encouraged throughout the test to perform a maximal effort. We considered that $\dot{\mathrm{V}} \mathrm{O}_{2 \max }$ was achieved when at least three of the following criteria were established: volitional exhaustion, theoretical maximal heart rate $\left(220\right.$-age \pm 10 beats $\left.\cdot \mathrm{min}^{-1}\right)$, Respiratory Exchange ratio $\left(\mathrm{RER}, \dot{\mathrm{V}} \mathrm{CO}_{2} / \mathrm{V}_{2}\right)$ above 1.1 , and a $\dot{\mathrm{V} O} \mathrm{O}_{2}$ plateau $\left(\leq 2.1 \mathrm{~mL} \cdot \mathrm{kg}^{-1} \cdot \mathrm{min}^{-1}\right)$ between the last two stages. Maximal Aerobic Power Output ( $\left.\mathrm{W}_{\text {aerobic max }}\right)$ was determined as the sum of the power output during the last stage fully completed $\left(\mathrm{W}_{\text {final }}\right)$ and the work rate increment (WR) multiplied by the fraction of time spent $(\mathrm{t})$ in the final unfinished stage as follows:

$$
W_{\text {aerobic } \max }=W_{\text {final }}+\left(\frac{t}{120} \times W R\right)
$$

\section{Dietary supplementation conditions}

Subjects were supplemented either in dietary $\mathrm{NO}_{3}{ }^{-}$with beetroot juice with an average nitrate content of $680 \mathrm{mg} \cdot \mathrm{L}^{-1}$ or apple-black currant juice used as a placebo had a nitrate content $<5$ $\mathrm{mg} \cdot \mathrm{L}^{-1}$ in a randomized, single blind, placebo controlled, crossover study. We used a random number table to assign the order of supplementation conditions to each participant. The experimenter engaged in the randomization process did not take part in the experimental visits. Because the placebo juice differs in taste, smell and appearance compared to beetroot juice supplementation, the purpose of the study was communicated to the participants as the comparison of exercise performance and physiological responses after the consumption of two vegetable beverages. There was a minor difference in the energy provided by BR (185 $\mathrm{kcal})$ and placebo $(225 \mathrm{kcal})$. Even although beetroot is rich in antioxidants, polyphenols and flavonoids, nitrate appears to be the active compounds responsible for the physiologic effects following beetroot juice supplementation. Lansley et al. found no reduction in $\dot{\mathrm{V}}_{2}$ during moderate- and severe-intensity exercise in healthy, recreationally active subjects following 
nitrate-depleted beetroot juice using an ion-exchange resin that selectively removes $\mathrm{NO}_{3}{ }^{-}$ions (42). The two beverages were purchased from PAJOTTENLANDER TM (Belgium). Drinks were distributed by an independent technician, not involved in the process of exercise testing. In the morning of the two days preceding each experimental visit, subjects ingested either $500 \mathrm{~mL}$ of beetroot juice or $500 \mathrm{~mL}$ of apple-black currant juice. On the day of each experimental visit, subjects were instructed to ingest $500 \mathrm{~mL}$ of BR or placebo $2 \mathrm{~h}$ before the time of their appointment at the laboratory so that the start of SIE tests corresponded to plasma nitrite peak. Pharmacokinetic data suggest that plasma nitrite will peak $2.5-3 \mathrm{~h}$ after ingestion of a single dose of BR (43). Subjects were instructed to refrain from caffeine and alcohol 6 and $24 \mathrm{~h}$ before the experimental visits. Participants were not asked to refrain consuming $\mathrm{NO}_{3}{ }^{-}$-rich food products, but they were instructed to replicate their food intake over the supplementation days between the two conditions and to complete a daily food diary for each supplementation period. In addition, subjects were finally instructed not to brush their teeth or to use mouthwash for $3 \mathrm{~h}$ after each BR or placebo intake (44).

\section{Supramaximal intermittent exercise tests}

After the preliminary visit, subjects performed cycling SIE tests during the two sessions 180min after the last dose of either ingested dietary nitrate or placebo supplementation. The exercise tests were completed on the same cycle ergometer than during the preliminary visit and separated by at least 2 weeks. Subjects warmed up for 5 min at $50 \%$ of maximal aerobic power output measured during the preliminary visit and were instructed to maintain a cycling cadence of $70 \mathrm{rpm}$. After a 2 min recovery period, subjects started the test consisting of work periods repetitions composed as follows: 15 -sec cycling bout at $170 \%$ of maximal aerobic power output interspersed with 30 -sec passive recovery periods. Before the test, subjects were 
instructed to reach as quickly as possible the targeted pedaling frequency of $90 \mathrm{rpm}$ during each 15-s cycling exercise bouts. Subjects started pedaling after a $3 \mathrm{sec}$ countdown by one of the experimenters, when they reached $50 \mathrm{rpm}$ the resistance corresponding to $170 \%$ of maximal aerobic power output was automatically applied with the Monark Software (Monark Anaerobic Test, MONARK EXERCISE TM, Sweden). Subjects recovered passively between each work period. The test was stopped when subjects indicated volitional exhaustion or when they were no longer able to maintain a pedaling frequency above $87 \mathrm{rpm}$ during the 5 last seconds of a 15 -sec cycling bout.

\section{Gas exchange measurement}

$\dot{\mathrm{V}} \mathrm{O}_{2}, \mathrm{CO}_{2}$ output $\left(\dot{\mathrm{V} C O}{ }_{2}\right)$, Respiratory Exchange Ratio $\left(\mathrm{RER}: \dot{\mathrm{V}} \mathrm{CO}_{2} / \dot{\mathrm{VO}}_{2}\right)$, Minute Ventilation ( $\dot{\mathrm{V} E})$ were measured breath-by-breath through a gas exchange measurement system $\left(\mathrm{K} 4 \mathrm{~b}_{2}\right.$, COSMED TM, Italy) during the graded maximal exercise test and SIE tests. Before each test, the gas analyzer was calibrated with ambient air and a gas mixture of known concentration $\left(\mathrm{O}_{2}: 16 \%, \mathrm{CO}_{2}: 5 \%\right)$, and the turbine flowmeter was calibrated with a $3 \mathrm{~L}$ syringe. Gas exchange data were recorded on a computer for later analysis. Heart rate was continuously recorded with a heart rate monitor (S810, POLAR TM, Finland).

\section{Local muscle parameters}

The changes in local muscle microvascular oxygenation, deoxygenation and total-hemoglobin volume of the vastus lateralis muscle were continuously measured during SIE tests by NIRS (Oxymon, ARTINIS MEDICAL SYSTEM TM, Netherlands). Briefly, the NIRS system measures the change in light absorption by hemoglobin $(\mathrm{Hb})$ and myoglobin $(\mathrm{Mb})$, which is related to $\mathrm{Hb}$ and $\mathrm{Mb} \mathrm{O}_{2}$ saturation. The two wavelengths emitting (780 and 850nm) and 
receiving optodes were spaced out of $4 \mathrm{~cm}$ and were placed at midway between the lateral condyle of the knee and the greater trochanter of the femur. Optodes were taped to the skin with adhesive strapping, covered with a dense black cloth to minimize exogenous light contamination, and wrapped with an elastic bandage to avoid any movement during the exercise tests. The location of the optodes was marked with a permanent pen during the first experimental visit to place them at the same location during the second experimental visit. NIRS signal acquisition was performed at $10 \mathrm{~Hz}$ with the Oxysoft software (Oxysoft, ARTINIS MEDICAL SYSTEM TM, Netherlands), and data were exported at $1 \mathrm{~Hz}$ for later analysis. Three indexes of muscle oxy-, deoxy-, and total-hemoglobin volume were derived from NIRS measurements of the vastus lateralis muscle: changes from the resting baseline in oxygenated hemoglobin $\left(\mathrm{HbO}_{2}\right)$ and deoxygenated hemoglobin $(\mathrm{HHb})$ were respectively estimates of muscle oxygenation and fractional $\mathrm{O}_{2}$ extraction; total hemoglobin $(\mathrm{THb})$ was calculated as the sum of $\mathrm{HbO}_{2}$ and $\mathrm{HHb}$ and was an estimate of the change in muscle microvascular blood volume.

\section{Blood pressure measurement}

Upon their arrival at the laboratory, subjects rested for $10 \mathrm{~min}$ in supine position on a medical exam table. Resting Systolic Blood Pressure (SBP), Diastolic Blood Pressure (DBP) and heart rate were measured in duplicate with an electronic sphygmomanometer (IntelliSense, OMRON TM, Netherlands) and then were averaged for analysis.

\section{Blood sampling and assessment}

After blood pressure measurements, blood sampling was performed through a catheter inserted in an antecubital vein. A first sample $(5 \mathrm{~mL})$ was collected 15 minutes before supramaximal intermittent exercise tests in an EDTA tube with subjects in a semi recumbent 
position. Twenty-five minutes after the end of exercise tests, a second sample was drawn with the same procedure. Samples were centrifuged at $3600 \mathrm{~g}$ and $4^{\circ} \mathrm{C}$ for $10 \mathrm{~min}$, and plasma was aliquoted and stored at $-80^{\circ} \mathrm{C}$ for later analysis.

Plasma $\mathrm{NO}_{\mathrm{x}}$ concentrations were determined by the Griess method with a commercial kit (CAYMAN $\mathrm{NO}_{3}{ }^{-}$colorimetric assay kit, Bertin Pharma TM, France).

\section{Data analysis}

Given each subject completed a number of repetitions different between BR and PL conditions, the experimental condition with the lowest number of repetitions completed was used as the trial reference and was compared to time matched data of the other experimental condition with the highest number of repetitions. The time-matched gas exchange and NIRS variables compared between the two conditions are denoted TM-throughout the Results and Discussion sections. Mean gas exchange values were calculated over the whole exercise duration, only TM-work bouts, only TM-recovery bouts and combined TM-work and recovery periods, respectively. The amplitude of change for $\dot{\mathrm{V}} \mathrm{O}_{2}, \dot{\mathrm{V}} \mathrm{CO}_{2}$, and $\dot{\mathrm{V} E}\left(\Delta \dot{\mathrm{V}} \mathrm{O}_{2}\right.$, $\Delta \dot{\mathrm{V}} \mathrm{CO}_{2}$, and $\Delta \dot{\mathrm{V} E}$, respectively) between work and recovery periods during TM-repetitions was also calculated.

All NIRS variables were expressed as relative changes from baseline values. Baseline values for $\mathrm{HbO}_{2}, \mathrm{HHb}$, and $\mathrm{THb}$ were measured during the last 30-s of a 2-min resting period with subjects in a seated position before the warm-up for the exercise test. The maximal values for $\mathrm{HHb}$ and $\mathrm{THb}$, and the minimal and maximal values for $\mathrm{HbO}_{2}\left(\mathrm{HbO}_{2}\right.$ min and $\mathrm{HbO}_{2}$ max, respectively) were determined during each experimental condition. The areas under the curves (AUC) for $\mathrm{HbO}_{2}\left(\mathrm{AUC}-\mathrm{HbO}_{2}+\right), \mathrm{HHb}(\mathrm{AUC}-\mathrm{HHb})$, and $\mathrm{THb}(\mathrm{AUC}-\mathrm{THb})$ were calculated by the trapezoidal method over the duration of combined TM-work and recovery periods. The 
AUC were calculated to provide an integrated index of muscle oxy-, deoxy-, and totalhemoglobin volume. During exercise, changes in $\mathrm{HbO}_{2}$ occur below the baseline level; the AUC for $\mathrm{HbO}_{2}$ was also determined below the baseline level (AUC- $\mathrm{HbO}_{2}-$ ).

\section{Statistical analysis}

Statistical analyses were run with $\mathrm{R}$ software ( $\mathrm{R}$ version 3.2.5, R Foundation for Statistical Computing, Vienna, Austria). Data are expressed as mean \pm standard deviation (SD) unless otherwise stated. Normal distribution of the data was assessed by the Kolmogorov-Smirnov test. A bilateral Student paired t-test was used to compare the dependent variables (gas exchange values, NIRS-derived indexes and exercise performance parameters) from SIE tests between the experimental conditions (independent variables: beetroot juice supplementation vs. placebo). Plasma $\mathrm{NO}_{\mathrm{x}}$ levels were analyzed by two-way ANOVA for repeated measures to compare the experimental conditions (beetroot juice supplementation vs. placebo) before and after the exercise test. Post-hoc analysis was then performed for dependent samples, as appropriate. Pearson's product moment correlation coefficients were calculated to assess the relationships between the change in $\mathrm{NO}_{\mathrm{x}}$ and the changes in exercise tolerance and physiological parameters. Statistical significance was set at $p<0.05$. 


\section{Results}

Plasma NOx levels

Plasma $\mathrm{NO}_{\mathrm{x}}$ levels were significantly higher in BR condition compared to PL condition before (BR: $91.05 \pm 30.01 \mu \mathrm{M}$ vs. PL: $21.41 \pm 7.59 \mu \mathrm{M} ; \mathrm{p}<0.01$ ) and after supramaximal intermittent exercise (BR: $78.23 \pm 14.67 \mu \mathrm{M}$ vs. PL: $20.17 \pm 6.17 \mu \mathrm{M} ; \mathrm{p}<0.01$ ).

\section{Exercise performance}

Individual number of repetitions is displayed in figure 1. The number of work periods completed was not significantly different between the two conditions (BR: 13.9 \pm 4.0 reps, PL: $14.2 \pm 4.5$ reps). The targeted power output representing $170 \%$ of maximal aerobic power output was 555.3 $\pm 50.3 \mathrm{~W}$. Mean Power Output were 579.2 $\pm 57.7 \mathrm{~W}$ during the BR condition and $578.9 \pm 54.3 \mathrm{~W}$ during the placebo condition. There was no difference for total work performed during the two conditions (BR: $121 \pm 38 \mathrm{~kJ}, \mathrm{PL}: 121 \pm 29 \mathrm{~kJ})$. The number of work bouts completed was not significantly associated with plasma $\mathrm{NO}_{\mathrm{x}}$ levels in any of the two conditions both before (BR: $r=-0.05$, PL: $r=-0.44)$ and after (BR: $r=-0.26$, PL: $r=-0.45)$ SIE test. The order of the experimental sessions did not significantly affect exercise performance ( $1^{\text {st }}$ session: $13.2 \pm 3.7$ reps, $2^{\text {nd }}$ session: $14.8 \pm 4.6$ reps $)$.

\section{-Figure 1 here-}


There were no significant differences for $\dot{\mathrm{V}} \mathrm{O}_{2}, \dot{\mathrm{V}} \mathrm{CO}_{2}$ and $\dot{\mathrm{V} E}$ between the $\mathrm{BR}$ and placebo conditions for the whole exercise, the first three work and recovery periods, and TM-work and recovery periods (see Figure 2). Heart rate was also similar between the two conditions for the whole exercise (BR: 159.9 $\pm 9.0 \mathrm{bpm}, \mathrm{PL}: 156.9 \pm 15.4 \mathrm{bpm})$ and for TM-periods (BR: 170.4 $\pm 14.7 \mathrm{bpm}, \mathrm{PL}: 172.0 \pm 7.1 \mathrm{bpm})$. There was no significant association between the changes in plasma $\mathrm{NO}_{\mathrm{x}}$ levels and the changes of $\mathrm{VO}_{2}$ in any of the two conditions both before (BR: $\mathrm{r}=0.12$, PL: $\mathrm{r}=0.19$ for time-matched work+recovery periods) and after (BR: $\mathrm{r}=0.244$, PL: $\mathrm{r}=0.325$ for time-matched work + recovery periods) SIE test. All correlations between plasma $\mathrm{NO}_{\mathrm{x}}$ levels and $\mathrm{V}_{2}$ changes are reported in Supplemental online Table 3. Results for gas exchange parameters and heart rate during exercise tests periods between BR and PL conditions are shown in Supplemental online Table 1.

\section{- Figure 2 here -}

\section{NIRS-derived parameters and resting blood pressure}

Results from NIRS measurements are displayed in Table 2. At baseline, $\mathrm{HbO}_{2}, \mathrm{HHb}$, and $\mathrm{THb}$ were not significantly different between the two conditions. During exercise, the maximal values of $\mathrm{HbO}_{2}, \mathrm{HHb}$, and $\mathrm{THb}$ were not significantly different between the two conditions. AUC- $\mathrm{HbO}_{2}+$ and AUC-HbO $2-$, AUC-HHb, and AUC-THb did not differ between the BR condition and placebo. The changes in plasma $\mathrm{NO}_{\mathrm{x}}$ levels were not significantly associated with the changes in fractional $\mathrm{O}_{2}$ extraction (before SIE test: $\mathrm{BR} r=0.37$, PL: $\mathrm{r}=0.39$; after SIE test: BR r=0.34, PL: $r=-0.03$ ) and muscle microvascular blood volume (before SIE test: BR $r=0.22$, PL: $r=0.32$; after SIE test: $B R \quad r=0.15$, PL: $r=-0.19$ ) during time-matched 
work + recovery periods in any of the two conditions. All correlations between plasma $\mathrm{NO}_{\mathrm{x}}$ levels and changes in NIRS-derived parameters are reported in Supplemental online Table 3. There was no significant effect of BR supplementation on SBP, DBP, and heart rate at rest (Supplemental online Table 2).

- Table 2 here - 


\section{Discussion}

The main finding of our study is the lack of improvement in tolerance to SIE after dietary nitrate supplementation in athletes with a high level of aerobic fitness $\left(\mathrm{V}_{2 \mathrm{max}}>65 \mathrm{~mL} \cdot \mathrm{kg}^{-}\right.$ $\left.{ }^{1} \cdot \mathrm{min}^{-1}\right)$. The present study, to our knowledge, is the first to investigate the exercise tolerance to SIE and to measure gas exchange and local muscle $\mathrm{O}_{2}$ delivery and extraction in elite endurance athletes. Regardless of the aerobic fitness status of participants, a few studies have questioned whether $\mathrm{NO}_{3}{ }^{-}$supplementation increases tolerance to SIE. These studies showed either an impaired (20), unchanged $(12,18,20,21)$ or improved performance $(19,21)$.

High aerobic fitness is likely a major factor contributing to the lack of effect of $\mathrm{NO}_{3}{ }^{-}$ supplementation on exercise performance $(26,27)$. Previous studies showed that 1-day (45-49) and 6-days of dietary $\mathrm{NO}_{3}{ }^{-}$supplementation $(12,49,50)$ did not improve exercise performance during running $(45,46,48,50)$ and cycling time-trials $(12,47,49)$ in endurance athletes with $\dot{\mathrm{V}} \mathrm{O}_{2 \mathrm{max}}$ above $\sim 60 \mathrm{~mL} \cdot \mathrm{kg}^{-1} \cdot \mathrm{min}^{-1}$. Few nutritional supplementations have showed good benefits for exercise performance in elite athletes that are already well adapted to sport events due to chronic training adaptations (51). Investigations that address the effectiveness of dietary $\mathrm{NO}_{3}{ }^{-}$supplementation during supramaximal intensity exercise in elite endurance athletes are rare to date, with no improved exercise performance during $180 \mathrm{~m}$ running timetrial in elite cross-country skiers (48) and during repeated sprint capacity (6 x $20 \mathrm{~s}$ sprints, recovery $100 \mathrm{~s}$ ) in elite cyclists (12). It is striking that, with the same exercise protocol as in the present study, team sports athletes with moderate aerobic fitness $\left(\mathrm{V}_{2 \max }<55 \mathrm{~mL} \cdot \mathrm{kg}^{-}\right.$ ${ }^{1} \cdot \mathrm{min}^{-1}$ ) had a $20 \%$ increase in the mean number of repetitions completed when supplemented with dietary $\mathrm{NO}_{3}{ }^{-}$compared to placebo (19). In this exercise protocol, we fixed the recovery time at $30 \mathrm{~s}$ that is sufficiently long to allow the PCr pool to be resynthesized and the lactic acid accumulation to be limited (38). When subjects performed repeated-sprints with $30 \mathrm{~s}$ of 
recovery between each sprint, the power output was maintained by ATP that was derived mainly from PCr degradation and an increased contribution of aerobic metabolism (52). $\mathrm{PCr}$ recovery kinetics have been shown to be dependent on $\mathrm{O}_{2}$ availability in human skeletal muscle (53). The reasons for the absence of change in exercise tolerance in the present study may be related to characteristics of elite endurance athletes such a high proportion of type I muscle fibers (54), greater skeletal muscle capillary density (55) and increased oxidative capacity (56). Tesch et al. showed a similar PCr degradation between type I and type II muscle fibers in vastus lateralis muscle in active men following 30 maximal voluntary knee extensions (57). However, after 60 seconds of recovery, type I muscle fibers had a significant greater level of PCr relative to the initial level than type II muscle fibers (57). These results suggest that elite endurance athletes may already have an optimal rate of $\mathrm{PCr}$ resynthesis during recovery periods that could not be affected by dietary $\mathrm{NO}_{3}^{-}$supplementation.

Hernández et al. well showed that $\mathrm{NO}_{3}{ }^{-}$supplementation increased force production in type II, predominantly glycolytic, muscle fibers, but not in type I, highly oxidative, muscle fibers in mouse (58). The same authors reported an increase in the expression of the sarcoplasmic reticulum $\mathrm{Ca}^{2+}$-handling proteins only in type II muscle fibers of $\mathrm{NO}_{3}{ }^{-}$supplemented mouse. Further study is required to address whether $\mathrm{NO}_{3}{ }^{-}$supplementation elicits comparable specific physiological responses of type II muscle fibers to exercise in humans. One purpose of the present study was therefore to investigate subjects with high aerobic fitness who are known to have a high proportion of type I muscle fibers and a small proportion of type II muscle fibers (54). The unaltered exercise tolerance in the present study provides support to the hypothesis that increased NO bioavailability may have selective effects in subjects with a high proportion of type II muscle fibers $(19,59)$, or during exercise that elicits a high recruitment of type II muscle fibers $(23,60)$. 
There may be a need for higher $\mathrm{NO}_{3}^{-}$dose than what we used to elicit significant physiological effects and subsequent increase in exercise tolerance in athletes with high aerobic fitness $(14,26)$. Such athletes have indeed been shown to have already high plasma $\mathrm{NO}_{\mathrm{x}}$ levels $(34,61)$, and $\mathrm{NO}_{3}{ }^{-}$dose that are effective in population with lower aerobic fitness may be ineffective to increase $\mathrm{NO}_{\mathrm{x}}$ levels in this population. Indeed, highly trained rowers improved 2000-meter rowing performance when supplemented with $8.4 \mathrm{mmol}$, as did not with $4.2 \mathrm{mmol}$ of $\mathrm{NO}_{3}^{-}(62)$. Nitrate supplementation in the present study $\left(5.2 \mathrm{mmol} \cdot \mathrm{day}^{-1}\right)$ being only slightly higher than the lowest dose used by Hoon et al. may have been insufficient to elicit significant physiological effects (62). It is however to note that when using $\mathrm{NO}_{3}{ }^{-}$dose as high as $19.5 \mathrm{mmol}$ either acutely or during 8 days, Boorsma et al. showed no effect on 1500-m time trial performance of elite middle distance runners (14). Furthermore, the duration of $\mathrm{NO}_{3}^{-}$supplementation being ingested could be considered. Vanhatalo et al. showed that maximal aerobic power output of healthy, but not highly trained subjects, was significantly improved relative to placebo after 15 days of $\mathrm{NO}_{3}^{-}$supplementation, whereas there were no significant differences with a 5-day or acute supplementation (63). Studies with supplementation duration of at least 15 days have to our knowledge not been conducted in athletes with high aerobic fitness. However, studies comparing 6 to 8 days $\mathrm{NO}_{3}{ }^{-}$ supplementation in athletes with high $\dot{\mathrm{VO}}_{2 \text { max }}$ showed no additional benefit $(14,15)$, and $\mathrm{NO}_{3}{ }^{-}$ and $\mathrm{NO}_{2}^{-}$plasma levels were not greater after the long $\mathrm{NO}_{3}{ }^{-}$supplementation duration than the shorter one (15). In addition, a recent meta-analysis showed that features of the $\mathrm{NO}_{3}{ }^{-}$ supplementation (the dose of $\mathrm{NO}_{3}{ }^{-}$supplementation, the number of days of supplementation and the total amount ingested of $\mathrm{NO}_{3}^{-}$) were not associated with changes in physical performance in both non-athlete and athlete individuals (64). In all, further research is required to establish the real sufficient dose of $\mathrm{NO}_{3}^{-}$being ingested, if any, in order to enhance the responsiveness to $\mathrm{NO}_{3}{ }^{-}$supplementation in elite endurance athletes. 
Regarding the present study, plasma $\mathrm{NO}_{x}$ levels after dietary $\mathrm{NO}_{3}{ }^{-}$supplementation were lower than in previous studies in subjects with high aerobic fitness $(13,14,18,65)$. However, Porcelli et al. who also ultrafiltrated plasma samples and used the Griess assay, found levels similar to those that we report in the placebo and $\mathrm{NO}_{3}^{-}$supplemented conditions (26). It is to note that many studies do not report ultrafiltration of plasma samples, and that proteins may interfere with $\mathrm{NO}_{3}{ }^{-} \mathrm{NO}_{2}{ }^{-}$, resulting in erroneously high $\mathrm{NO}_{x}$ values (66). Finally, a number of studies have reported that resting plasma $\mathrm{NO}_{2}^{-}$levels were similar in elite athletes and nonathletes $(26,65)$, and that acute dietary $\mathrm{NO}_{3}{ }^{-}$supplementation in elite athletes with dose similar to that used in non-athletes $(614 \mathrm{mg})$ were able to elicit significant increase in plasma $\mathrm{NO}_{3}{ }^{-} \mathrm{NO}_{2}{ }^{-}$, but no change in performance $(13,18)$.

A second and important finding of the present study was that $\dot{\mathrm{V}} \mathrm{O}_{2}$, local muscle oxy-, deoxy-, and total-hemoglobin volume were unaffected by $\mathrm{NO}_{3}{ }^{-}$supplementation. These findings are in contrast to the repeatedly reported decrease in $\dot{\mathrm{VO}}_{2}$ during submaximal intensity exercise in subjects with lower $\dot{\mathrm{V}} \mathrm{O}_{2 \max }(5,28,29,32,67,68)$. Unchanged $\dot{\mathrm{V}} \mathrm{O}_{2}$ was previously reported in studies investigating the effects of $\mathrm{NO}_{3}^{-}$supplementation during supramaximal intensity exercise (19-21). The percentage of $\dot{\mathrm{V}} \mathrm{O}_{2 \max }$ elicited in the present study ( $\left.75 \%\right)$ was similar to that reported by Martin et al. who showed no improvement in exercise tolerance with $\mathrm{NO}_{3}{ }^{-}$ supplementation (20). In contrast, the team sports players that we previously investigated reached on average $85 \% \dot{\mathrm{V}} \mathrm{O}_{2 \max }$ and had a significant increase in exercise tolerance with $\mathrm{NO}_{3}{ }^{-}$supplementation (19). In the latter study, we also observed that $\mathrm{NO}_{3}{ }^{-}$supplementation was associated with significantly higher $\dot{\mathrm{V} E}$, and lower $\dot{\mathrm{V}} \mathrm{O}_{2}$ and $\dot{\mathrm{V}} \mathrm{CO}_{2}$ fluctuations. These responses to $\mathrm{NO}_{3}{ }^{-}$supplementation were not present in the current study. Even though it is unclear how these physiological changes contributed to increased exercise tolerance in previous study, their absence in the present study provide additional evidences that increasing NO bioavailability has different effects in endurance athletes with aerobic fitness levels. We 
however cannot fully exclude that $\mathrm{NO}_{3}{ }^{-}$supplementation would be effective in elite endurance athletes during intermittent exercise with work:recovery ratio periods that would elicit a higher percentage of $\dot{\mathrm{V}} \mathrm{O}_{2 \max }(21)$.

It has been established that high-intensity intermittent exercise heavily recruits type II muscle fibers (22), which are more sensitive to fatigue than type I muscle fibers (69). BR supplementation improves blood flow distribution toward type II muscle fibers (70) and increases microvascular $\mathrm{O}_{2}$ pressure in type II muscle fibers during exercise in rats (71). It is thus hypothesized that dietary $\mathrm{NO}_{3}{ }^{-}$supplementation may improve exercise tolerance during high-intensity intermittent exercise by better matching blood flow to metabolic rate across the working muscle (72). In accordance with this perspective, we have previously reported that 3day BR supplementation, similar to that used in the present study, enhances tolerance to exercise at supramaximal intensity with increased microvascular total-hemoglobin in the working muscle (19). However, to date, there has been no investigation of local muscle $\mathrm{O}_{2}$ delivery and extraction in athletes with high $\mathrm{V}_{2 \max }$ and a low proportion of type 2 muscle fibers supplemented in dietary $\mathrm{NO}_{3}{ }^{-}$during SIE. Using NIRS-derived indexes, we show that $\mathrm{O}_{2}$ extraction and local blood volume in muscle vastus lateralis were unaltered during SIE. Furthermore, the lack of differences for $\mathrm{HHb}$ parameters, in conjunction with similar changes in $\mathrm{HbO}_{2}$ and $\mathrm{THb}$ between $\mathrm{BR}$ and placebo conditions, provides additional supports that dietary $\mathrm{NO}_{3}{ }^{-}$did not affect muscle microvascular perfusion in elite endurance athletes during SIE. Our present findings were supported by a recent study that reported no effect of single dose of $\mathrm{BR}$ supplementation on muscle fractional $\mathrm{O}_{2}$ extraction and muscle $\mathrm{V}_{2}$ during sustained isometric exercise in moderately trained subjects (8). In the latter study, the lack of effect of BR supplementation was evident even when blood flow was obstructed to working muscles (8). 
Together, the absence of change in exercise tolerance and physiological responses after BR supplementation in elite endurance athletes could be a consequence of many adaptations resulting of chronic training such as enhanced NO bioavailability by an upregulation of NO synthase activity $(34,73)$, greater skeletal muscle capillary density (55), increased content of skeletal muscle $\mathrm{Ca}^{2+}$-handling proteins (74) and a lower proportion of type II muscle fibers (54).

\section{Study considerations}

The low number of subjects can be considered as a limitation of our study. We cannot exclude that a study including a higher number of subjects would have yielded different results. However, rather than including a large number of subjects, we recruited a well characterized population of healthy young men based on $\dot{\mathrm{V}} \mathrm{O}_{2 \max }$ above $65 \mathrm{~mL} \cdot \mathrm{kg}^{-1} \cdot \mathrm{min}^{-1}$ and participation to endurance competitive sports.

Another limitation of the study was the small dose of nitrate $\left(5.2 \mathrm{mmol} \cdot \mathrm{day}^{-1}\right)$ used in the present study. It has been suggested that the minimal effective dose required to enhance exercise performance in most individuals is $\geq 5 \mathrm{mmol}$ of $\mathrm{NO}_{3}^{-}$per serving $(75,76)$. However, a recent meta-analysis reported that the dose of $\mathrm{NO}_{3}{ }^{-}$supplemented and the total amount of $\mathrm{NO}_{3}{ }^{-}$ingested were not associated with changes in exercise performance in non-athletes and athletes (64). Thus, further research is needed to determine whether higher $\mathrm{NO}_{3}{ }^{-}$intake than in our study is required in athletes with high $\mathrm{V}_{2 \max }$ to improve the tolerance to supramaximal intensity intermittent exercise, although few beetroot juice products intended for athletes effectively provide $\geq 5 \mathrm{mmol}$ of $\mathrm{NO}_{3}{ }^{-}$per serving (76) 


\section{Conclusion}

Three days of $\mathrm{NO}_{3}{ }^{-}$-rich beetroot juice supplementation $\left(5.2 \mathrm{mmol} \cdot \mathrm{day}^{-1}\right)$ did not increase the tolerance to supramaximal intensity intermittent exercise in elite endurance athletes with high $\dot{\mathrm{V}} \mathrm{O}_{2 \mathrm{max}}$, and did not affect $\dot{\mathrm{VO}}_{2}$ and local muscle $\mathrm{O}_{2}$ delivery and extraction. This finding provides additional support to the hypothesis that beetroot juice supplementation is less effective to improve performance in endurance-trained athletes, even in the case of exercise modalities that are known to promote the effectiveness of dietary $\mathrm{NO}_{3}{ }^{-}$supplementation by recruiting a greater proportion of NO-sensitive type II muscle fibers. 


\section{Acknowledgments}

We are grateful to the athletes who took part to the study. We thank the nurses at the Haute Ecole Provinciale du Hainaut (Tournai, Belgium) for their assistance during the experimental protocol.

Authors J.A., J.B., S.B. and M.P.-C. conceived and designed the research; Authors J.A., J.B., F.-X.G., D.M., G.C., and M.P.-C conducted the research; Authors J.A., J.B., D.M., and M.P.C. analyzed the data or performed statistical analysis; Authors J.A., J.B., F.-X.G., G.C., D.M., S.B., and M.P.-C wrote the paper. M.P.-C. and J.A had primary responsibility for final content. All authors read and approved the final manuscript.

\section{Conflicts of interest and source of funding}

The authors do not have any conflicts of interest to disclose. No funding was received for this study. 


\section{References}

1. Gao Y. The multiple actions of NO. Pflugers Arch. 2010 May;459:829-39.

2. Förstermann U, Sessa WC. Nitric oxide synthases: regulation and function. Eur. Heart J. 2012 Apr;33:829-37, 837a-837d.

3. Lundberg JO, Weitzberg E, Gladwin MT. The nitrate-nitrite-nitric oxide pathway in physiology and therapeutics. Nat. Rev. Drug Discov. 2008 Feb;7:156-67.

4. McMahon NF, Leveritt MD, Pavey TG. The Effect of Dietary Nitrate Supplementation on Endurance Exercise Performance in Healthy Adults: A Systematic Review and MetaAnalysis. Sports Med. 2017 Apr;47:735-56.

5. Bailey SJ, Fulford J, Vanhatalo A, et al. Dietary nitrate supplementation enhances muscle contractile efficiency during knee-extensor exercise in humans. J. Appl. Physiol. 2010;109:135-48.

6. Larsen FJ, Schiffer TA, Borniquel S, et al. Dietary inorganic nitrate improves mitochondrial efficiency in humans. Cell Metab. 2011;13:149-59.

7. Whitfield J, Ludzki A, Heigenhauser GJF, et al. Beetroot juice supplementation reduces whole body oxygen consumption but does not improve indices of mitochondrial efficiency in human skeletal muscle. J. Physiol. 2016 Jan 15;594:421-35.

8. Papadopoulos S, Dipla K, Triantafyllou A, et al. Beetroot Increases Muscle Performance and Oxygenation During Sustained Isometric Exercise, but Does Not Alter Muscle Oxidative Efficiency and Microvascular Reactivity at Rest. J. Am. Coll. Nutr. 2018 Jul;37:361-72.

9. Larsen FJ, Schiffer TA, Borniquel S, et al. Dietary inorganic nitrate improves mitochondrial efficiency in humans. Cell Metab. 2011 Feb 2;13:149-59.

10. Bailey SJ, Fulford J, Vanhatalo A, et al. Dietary nitrate supplementation enhances muscle contractile efficiency during knee-extensor exercise in humans. J. Appl. Physiol. 2010 Jul;109:135-48.

11. Aucouturier J, Boissière J, Pawlak-Chaouch M, Cuvelier G, Gamelin F-X. Effect of dietary nitrate supplementation on tolerance to supramaximal intensity intermittent exercise. Nitric Oxide. 2015 Sep 15;49:16-25.

12. Christensen PM, Nyberg M, Bangsbo J. Influence of nitrate supplementation on $\mathrm{VO}_{2}$ kinetics and endurance of elite cyclists. Scand. J. Med. Sci. Sports. 2013 Feb;23:e21-31.

13. Peacock $\mathrm{O}$, Tjønna AE, James $\mathrm{P}$, et al. Dietary nitrate does not enhance running performance in elite cross-country skiers. Med. Sci. Sports Exerc. 2012 Nov;44:2213-9.

14. Boorsma RK, Whitfield J, Spriet LL. Beetroot juice supplementation does not improve performance of elite 1500-m runners. Med. Sci. Sports Exerc. 2014 Dec;46:2326-34. 
15. Nyakayiru J, Jonvik KL, Pinckaers PJM, Senden J, Van Loon LJC, Verdijk LB. No Effect of Acute and 6-Day Nitrate Supplementation on VO2 and Time-Trial Performance in Highly-Trained Cyclists. Int. J. Sport Nutr. Exerc. Metab. 2016 Sep 6;125.

16. MacLeod KE, Nugent SF, Barr SI, Koehle MS, Sporer BC, MacInnis MJ. Acute Beetroot Juice Supplementation Does Not Improve Cycling Performance in Normoxia or Moderate Hypoxia. Int. J. Sport Nutr. Exerc. Metab. 2015 Aug;25:359-66.

17. Shannon OM, Duckworth L, Barlow MJ, et al. Dietary nitrate supplementation enhances high-intensity running performance in moderate normobaric hypoxia, independent of aerobic fitness. Nitric Oxide. 2016 Sep 30;59:63-70.

18. Sandbakk SB, Sandbakk Ø, Peacock O, et al. Effects of acute supplementation of Larginine and nitrate on endurance and sprint performance in elite athletes. Nitric Oxide. 2015 Aug 1;48:10-5.

19. Aucouturier J, Boissière J, Pawlak-Chaouch M, Cuvelier G, Gamelin F-X. Effect of dietary nitrate supplementation on tolerance to supramaximal intensity intermittent exercise. Nitric Oxide. 2015 Sep 15;49:16-25.

20. Martin K, Smee D, Thompson KG, Rattray B. No improvement of repeated-sprint performance with dietary nitrate. Int. J. Sports Physiol. Perform. 2014 Sep;9:845-50.

21. Wylie LJ, Bailey SJ, Kelly J, Blackwell JR, Vanhatalo A, Jones AM. Influence of beetroot juice supplementation on intermittent exercise performance. Eur. J. Appl. Physiol. 2016 Feb;116:415-25.

22. Krustrup P, Mohr M, Steensberg A, Bencke J, Kjaer M, Bangsbo J. Muscle and blood metabolites during a soccer game: implications for sprint performance. Med. Sci. Sports Exerc. 2006 Jun;38:1165-74.

23. Jones AM, Ferguson SK, Bailey SJ, Vanhatalo A, Poole DC. Fiber Type-Specific Effects of Dietary Nitrate. Exerc. Sport Sci. Rev. 2016 Apr;44:53-60.

24. Vanhatalo A, Fulford J, Bailey SJ, Blackwell JR, Winyard PG, Jones AM. Dietary nitrate reduces muscle metabolic perturbation and improves exercise tolerance in hypoxia. J. Physiol. 2011 Nov 15;589:5517-28.

25. Vanhatalo A, Jones AM, Blackwell JR, Winyard PG, Fulford J. Dietary nitrate accelerates postexercise muscle metabolic recovery and $\mathrm{O} 2$ delivery in hypoxia. J. Appl. Physiol. 2014 Dec 15;117:1460-70.

26. Porcelli S, Ramaglia M, Bellistri G, et al. Aerobic Fitness Affects the Exercise Performance Responses to Nitrate Supplementation. Med. Sci. Sports Exerc. 2015 Aug;47:1643-51.

27. Hoon MW, Johnson NA, Chapman PG, Burke LM. The effect of nitrate supplementation on exercise performance in healthy individuals: a systematic review and meta-analysis. Int. J. Sport Nutr. Exerc. Metab. 2013 Oct;23:522-32. 
28. Bailey SJ, Winyard P, Vanhatalo A, et al. Dietary nitrate supplementation reduces the $\mathrm{O} 2$ cost of low-intensity exercise and enhances tolerance to high-intensity exercise in humans. J. Appl. Physiol. 2009;107:1144-55.

29. Lansley KE, Winyard PG, Fulford J, et al. Dietary nitrate supplementation reduces the $\mathrm{O} 2$ cost of walking and running: a placebo-controlled study. J. Appl. Physiol. 2011 Mar;110:591-600.

30. Nyakayiru J, Jonvik KL, Trommelen J, et al. Beetroot Juice Supplementation Improves High-Intensity Intermittent Type Exercise Performance in Trained Soccer Players. Nutrients. 2017 Mar 22;9.

31. Thompson KG, Turner L, Prichard J, et al. Influence of dietary nitrate supplementation on physiological and cognitive responses to incremental cycle exercise. Respir. Physiol. Neurobiol. 2014;193:11-20.

32. Wylie LJ, Kelly J, Bailey SJ, et al. Beetroot juice and exercise: pharmacodynamic and dose-response relationships. J. Appl. Physiol. 2013 Aug 1;115:325-36.

33. Wylie LJ, Mohr M, Krustrup P, et al. Dietary nitrate supplementation improves team sport-specific intense intermittent exercise performance. Eur. J. Appl. Physiol. 2013;113:1673-84.

34. Totzeck M, Hendgen-Cotta UB, Rammos C, et al. Higher endogenous nitrite levels are associated with superior exercise capacity in highly trained athletes. Nitric Oxide. 2012;27:75-81.

35. Bernard T, Hausswirth C, Le Meur Y, Bignet F, Dorel S, Brisswalter J. Distribution of power output during the cycling stage of a Triathlon World Cup. Med. Sci. Sports Exerc. 2009 Jun;41:1296-302.

36. Ebert TR, Martin DT, McDonald W, Victor J, Plummer J, Withers RT. Power output during women's World Cup road cycle racing. Eur. J. Appl. Physiol. 2005 Dec;95:529_ 36.

37. Domínguez R, Maté-Muñoz JL, Cuenca E, et al. Effects of beetroot juice supplementation on intermittent high-intensity exercise efforts. J. Int. Soc. Sports Nutr. 2018;15:2.

38. Billat LV. Interval training for performance: a scientific and empirical practice. Special recommendations for middle- and long-distance running. Part II: anaerobic interval training. Sports Med. 2001 Feb;31:75-90.

39. Tabata I, Irisawa K, Kouzaki M, Nishimura K, Ogita F, Miyachi M. Metabolic profile of high intensity intermittent exercises. Med. Sci. Sports Exerc. 1997 Mar;29:390-5.

40. Brandon LJ. Physiological factors associated with middle distance running performance. Sports Med. 1995 Apr;19:268-77.

41. Midgley AW, McNaughton LR, Wilkinson M. Is there an optimal training intensity for enhancing the maximal oxygen uptake of distance runners?: empirical research findings, 
current opinions, physiological rationale and practical recommendations. Sports Med. 2006;36:117-32.

42. Lansley KE, Winyard PG, Fulford J, et al. Dietary nitrate supplementation reduces the O2 cost of walking and running: a placebo-controlled study. J. Appl. Physiol. 2011 Mar;110:591-600.

43. Webb AJ, Patel N, Loukogeorgakis S, et al. Acute blood pressure lowering, vasoprotective, and antiplatelet properties of dietary nitrate via bioconversion to nitrite. Hypertens. 2008 Mar;51:784-90.

44. Govoni M, Jansson EA, Weitzberg E, Lundberg JO. The increase in plasma nitrite after a dietary nitrate load is markedly attenuated by an antibacterial mouthwash. Nitric Oxide. 2008 Dec;19:333-7.

45. Peacock O, Tjønna AE, James $\mathrm{P}$, et al. Dietary nitrate does not enhance running performance in elite cross-country skiers. Med. Sci. Sports Exerc. 2012 Nov;44:2213-9.

46. Boorsma RK, Whitfield J, Spriet LL. Beetroot juice supplementation does not improve performance of elite 1500-m runners. Med. Sci. Sports Exerc. 2014 Dec;46:2326-34.

47. MacLeod KE, Nugent SF, Barr SI, Koehle MS, Sporer BC, MacInnis MJ. Acute Beetroot Juice Supplementation Does Not Improve Cycling Performance in Normoxia or Moderate Hypoxia. Int. J. Sport Nutr. Exerc. Metab. 2015 Aug;25:359-66.

48. Sandbakk SB, Sandbakk $\varnothing$, Peacock O, et al. Effects of acute supplementation of Larginine and nitrate on endurance and sprint performance in elite athletes. Nitric Oxide. 2015 Aug 1;48:10-5.

49. Nyakayiru JM, Jonvik KL, Pinckaers PJM, Senden J, van Loon LJC, Verdijk LB. No Effect of Acute and 6-Day Nitrate Supplementation on VO2 and Time-Trial Performance in Highly Trained Cyclists. Int. J. Sport Nutr. Exerc. Metab. 2017 Feb;27:11-7.

50. Porcelli S, Ramaglia M, Bellistri G, et al. Aerobic Fitness Affects the Exercise Performance Responses to Nitrate Supplementation. Med. Sci. Sports Exerc. 2015 Aug;47:1643-51.

51. Maughan RJ, Burke LM, Dvorak J, et al. IOC consensus statement: dietary supplements and the high-performance athlete. Br. J. Sports Med. 2018 Apr;52:439-55.

52. Gaitanos GC, Williams C, Boobis LH, Brooks S. Human muscle metabolism during intermittent maximal exercise. J. Appl. Physiol. 1993 Aug;75:712-9.

53. Haseler LJ, Hogan MC, Richardson RS. Skeletal muscle phosphocreatine recovery in exercise-trained humans is dependent on O2 availability. J. Appl. Physiol. 1999 Jun;86:2013-8.

54. Abernethy PJ, Thayer R, Taylor AW. Acute and chronic responses of skeletal muscle to endurance and sprint exercise. A review. Sports Med. 1990 Dec;10:365-89. 
55. Jensen L, Bangsbo J, Hellsten Y. Effect of high intensity training on capillarization and presence of angiogenic factors in human skeletal muscle. J. Physiol. 2004 Jun $1 ; 557: 571-82$.

56. Hopker J, Passfield L, Coleman D, Jobson S, Edwards L, Carter H. The effects of training on gross efficiency in cycling: a review. Int. J. Sports Med. 2009 Dec;30:84550 .

57. Tesch PA, Thorsson A, Fujitsuka N. Creatine phosphate in fiber types of skeletal muscle before and after exhaustive exercise. J. Appl. Physiol. 1989 Apr;66:1756-9.

58. Hernández A, Schiffer TA, Ivarsson N, et al. Dietary nitrate increases tetanic [Ca2+]i and contractile force in mouse fast-twitch muscle. J. Physiol. 2012 Aug 1;590:3575-83.

59. Jonvik KL, Nyakayiru J, van Dijk JW, et al. Repeated-sprint performance and plasma responses following beetroot juice supplementation do not differ between recreational, competitive and elite sprint athletes. Eur. J. Sport Sci. 2018 Feb 7;1-10.

60. Breese BC, Mcnarry MA, Marwood S, Blackwell JR, Bailey SJ, Jones AM. Beetroot juice supplementation speeds $\mathrm{O} 2$ uptake kinetics and improves exercise tolerance during severe-intensity exercise initiated from an elevated metabolic rate. Am. J. Physiol. Regul. Integr. Comp. Physiol. 2013;305:R1441-50.

61. Jungersten L, Ambring A, Wall B, Wennmalm A. Both physical fitness and acute exercise regulate nitric oxide formation in healthy humans. J. Appl. Physiol. 1997 Mar;82:760-4.

62. Hoon MW, Jones AM, Johnson NA, et al. The effect of variable doses of inorganic nitrate-rich beetroot juice on simulated 2,000-m rowing performance in trained athletes. Int. J. Sports Physiol. Perform. 2014 Jul;9:615-20.

63. Vanhatalo A, Bailey SJ, Blackwell JR, et al. Acute and chronic effects of dietary nitrate supplementation on blood pressure and the physiological responses to moderate-intensity and incremental exercise. Am. J. Physiol. Regul. Integr. Comp. Physiol. 2010 Oct;299:R1121-1131.

64. Campos HO, Drummond LR, Rodrigues QT, et al. Nitrate supplementation improves physical performance specifically in non-athletes during prolonged open-ended tests: a systematic review and meta-analysis. Br. J. Nutr. 2018 Mar;119:636-57.

65. Christensen PM, Petersen NK, Friis SN, Weitzberg E, Nybo L. Effects of nitrate supplementation in trained and untrained muscle is modest with initial high plasma nitrite levels. Scand. J. Med. Sci. Sports. 2017 Feb 6;

66. Tsikas D. Analysis of nitrite and nitrate in biological fluids by assays based on the Griess reaction: appraisal of the Griess reaction in the L-arginine/nitric oxide area of research. J. Chromatogr. B Analyt. Technol. Biomed. Life. Sci. 2007 May 15;851:5170.

67. Jones AM. Dietary nitrate supplementation and exercise performance. Sports Med. 2014 May;44 Suppl 1:S35-45. 
68. Pawlak-Chaouch M, Boissière J, Gamelin FX, Cuvelier G, Berthoin S, Aucouturier J. Effect of dietary nitrate supplementation on metabolic rate during rest and exercise in human: A systematic review and a meta-analysis. Nitric Oxide. 2016 Feb;53:65-76.

69. Lucía A, Sánchez O, Carvajal A, Chicharro JL. Analysis of the aerobic-anaerobic transition in elite cyclists during incremental exercise with the use of electromyography. Br. J. Sports Med. 1999 Jun;33:178-85.

70. Ferguson SK, Hirai DM, Copp SW, et al. Impact of dietary nitrate supplementation via beetroot juice on exercising muscle vascular control in rats. J. Physiol. 2013;591:54757.

71. Ferguson SK, Holdsworth CT, Wright JL, et al. Microvascular oxygen pressures in muscles comprised of different fiber types: Impact of dietary nitrate supplementation. Nitric Oxide. 2015 Aug 1;48:38-43.

72. Jones AM. Influence of dietary nitrate on the physiological determinants of exercise performance: a critical review. Appl. Physiol. Nutr. Metab. 2014 Sep;39:1019-28.

73. McConell GK, Bradley SJ, Stephens TJ, Canny BJ, Kingwell BA, Lee-Young RS. Skeletal muscle nNOS mu protein content is increased by exercise training in humans. Am. J. Physiol. Regul. Integr. Comp. Physiol. 2007 Aug;293:R821-828.

74. Kinnunen S, Mänttäri S. Specific effects of endurance and sprint training on protein expression of calsequestrin and SERCA in mouse skeletal muscle. J. Muscle Res. Cell Motil. 2012 Jun;33:123-30.

75. Van De Walle GP, Vukovich MD. The Effect of Nitrate Supplementation on Exercise Tolerance and Performance: A Systematic Review and Meta-Analysis. J. Strength Cond. Res. 2018 Jun;32:1796-808.

76. Gallardo EJ, Coggan AR. What's in Your Beet Juice? Nitrate and Nitrite Content of Beet Juice Products Marketed to Athletes. Int. J. Sport Nutr. Exerc. Metab. 2018 Oct $9 ; 1-17$. 


\section{Tables}

Table 1. Characteristics of the subjects included in the study $(n=9)$

\begin{tabular}{ll}
\hline Parameters & Mean \pm SD
\end{tabular}

\begin{tabular}{ll}
\hline \hline Age (years) & $21.7 \pm 3.7$
\end{tabular}

Body Mass (kg)

$66.8 \pm 8.5$

Height (m)

$1.80 \pm 0.07$

Body Fat (\%)

$11.1 \pm 2.4$

Maximal aerobic power (W)

$327 \pm 30$

$\dot{\mathrm{V}} \mathrm{O}_{2 \max }\left(\mathrm{mL} \cdot \mathrm{kg}^{-1} \cdot \mathrm{min}^{-1}\right)$

$71.1 \pm 5.2$

Values are mean \pm SD. 
Table 2. Effects of a 3-day dietary nitrate supplementation (beetroot juice) on NIRS-derived parameters of the vastus lateralis muscle during supramaximal intensity intermittent exercise tests.

\section{Beetroot Juice}

\section{Placebo}

\begin{tabular}{|c|c|c|c|}
\hline \multirow[t]{5}{*}{$\mathrm{HbO}_{2}$} & Baseline & $39.3 \pm 14.1$ & $40.3 \pm 14.1$ \\
\hline & Maximal & $14.3 \pm 7.9$ & $12.7 \pm 3.8$ \\
\hline & TM-AUC+ & $1710.8 \pm 1083.7$ & $1911.1 \pm 1026.3$ \\
\hline & Minimal & $-14.5 \pm 6.4$ & $-15.0 \pm 7.3$ \\
\hline & TM-AUC- & $3178.5 \pm 1597.5$ & $4013.3 \pm 2166.7$ \\
\hline \multirow[t]{3}{*}{ HHb } & Baseline & $45.1 \pm 18.2$ & $44.9 \pm 17.7$ \\
\hline & Maximal & $25.6 \pm 12.7$ & $21.8 \pm 6.5$ \\
\hline & TM-AUC & $6619.7 \pm 875.8$ & $6332.7 \pm 1336.8$ \\
\hline \multirow[t]{3}{*}{ THb } & Baseline & $83.0 \pm 33.4$ & $85.2 \pm 31.2$ \\
\hline & Maximal & $15.4 \pm 12.3$ & $15.6 \pm 5.2$ \\
\hline & TM-AUC & $6816.9 \pm 1463.1$ & $6771.5 \pm 3004.5$ \\
\hline
\end{tabular}

Values are mean \pm SD. AUC: Area Under the Curve, $\mathrm{HbO}_{2}$ : oxygenated hemoglobin, $\mathrm{HHb}$ : deoxygenated hemoglobin, $\mathrm{THb}$ : total hemoglobin, TM- denotes time-matched comparison for 3 successive work+recovery periods, TM-AUC + and TM-AUC- indicate the areas under curves calculated for $\mathrm{HbO}_{2}$ data above and below the resting baseline values, respectively. 


\section{Figures}

Figure 1. Individual data points for the number of repetitions completed before volitional exhaustion during supramaximal intensity intermittent exercise tests following a placebo and a beetroot juice supplementation. Red squares indicate the mean number of work periods completed for each condition.

Figure 2. Bar plots of gas exchange and heart rate parameters during supramaximal intensity intermittent exercise tests following a placebo (white bars) and a beetroot juice supplementation (grey bars). Data were calculated over the whole duration (Whole session), the first three work and recovery periods (First 3 bouts), and TM-work and recovery periods (Last 3 bouts) for $\dot{\mathrm{VO}}_{2}(\mathrm{~A}), \dot{\mathrm{V} C O}{ }_{2}(\mathrm{~B}), \dot{\mathrm{VE}}(\mathrm{C})$ and heart rate (D). 


\section{Supplemental Online Data}

Supplemental Online Table 1. Effects of a 3-day dietary nitrate supplementation (beetroot juice) on fluctuations of gas exchange parameters and heart rate during supramaximal intensity intermittent exercise tests.

Supplemental Online Table 2. Effects of a 3-day dietary nitrate supplementation (beetroot juice) on resting heart rate and blood pressure.

Supplemental Online Table 3. Pearson correlation coefficients of plasma $\mathrm{NO}_{\mathrm{x}}$ levels with changes in $\dot{\mathrm{VO}}_{2}$ and NIRS-derived parameters before and after supramaximal intermittent exercise (SIE) tests. 

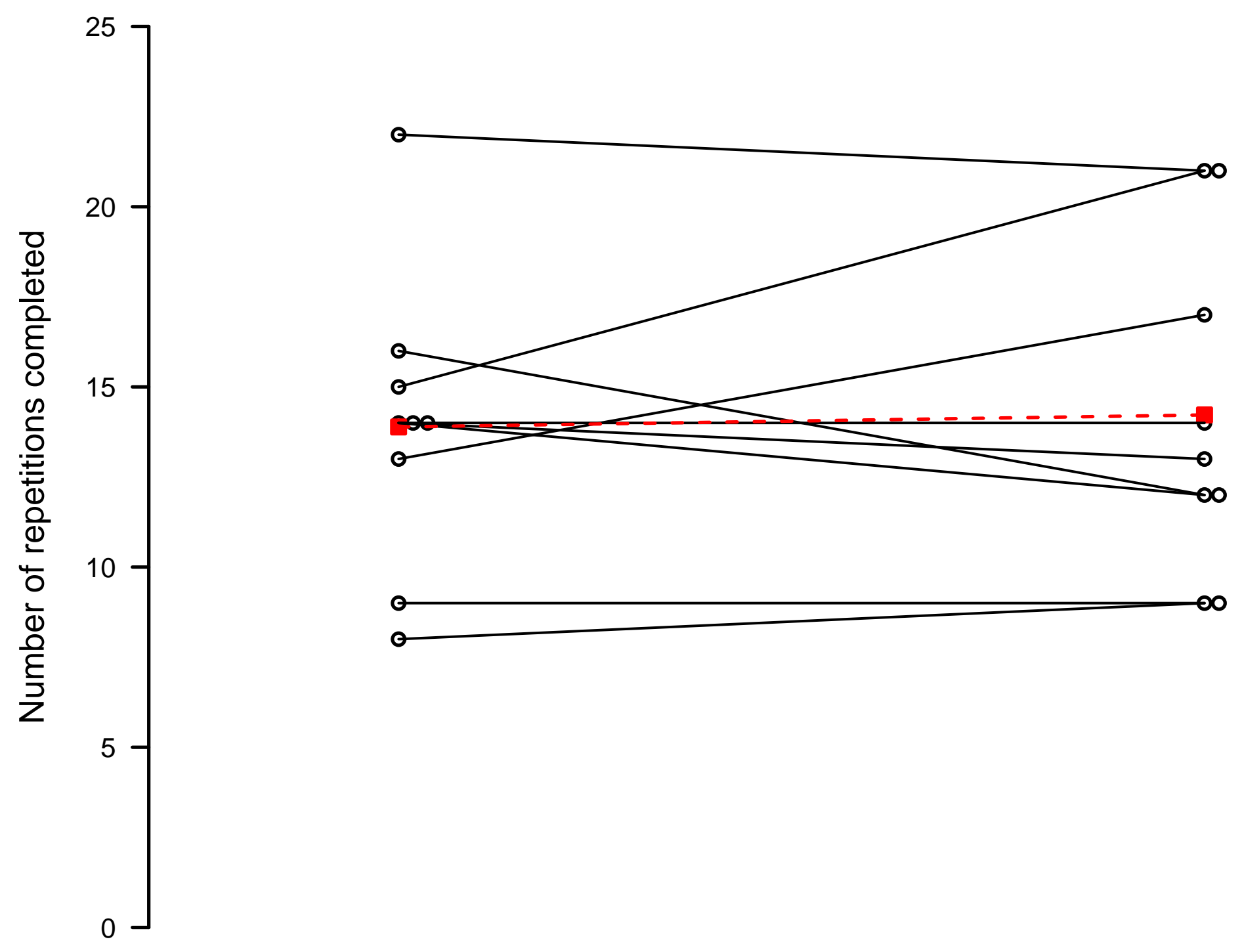
A

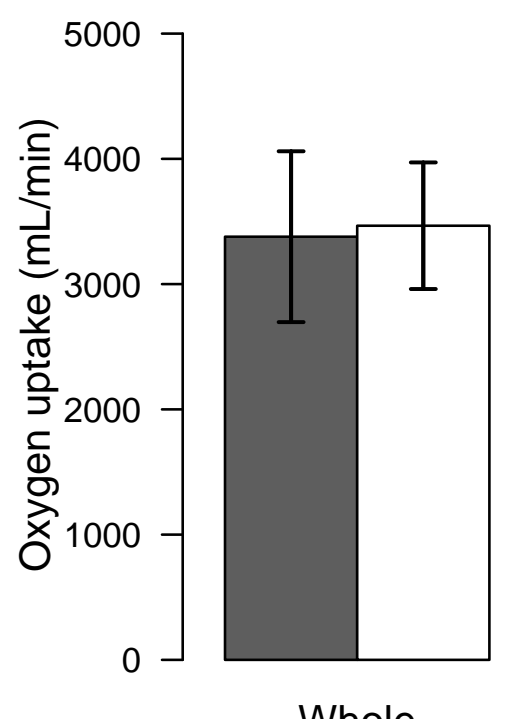

Whole

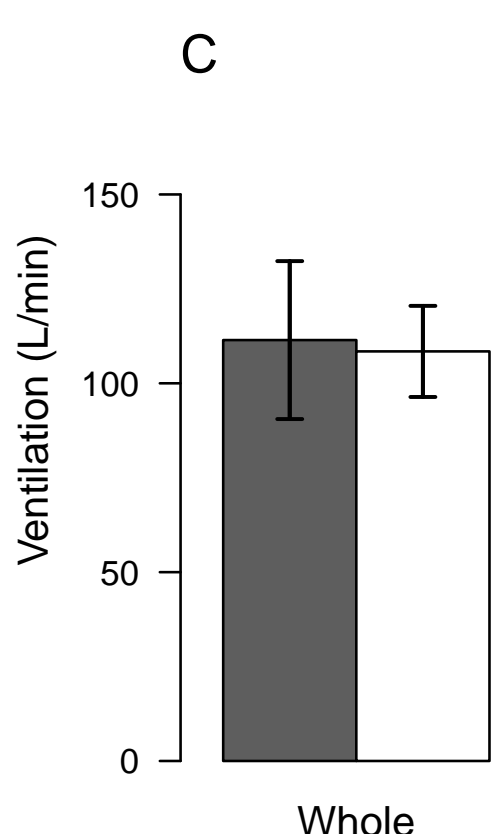

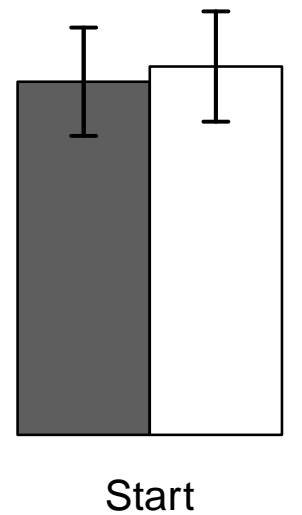
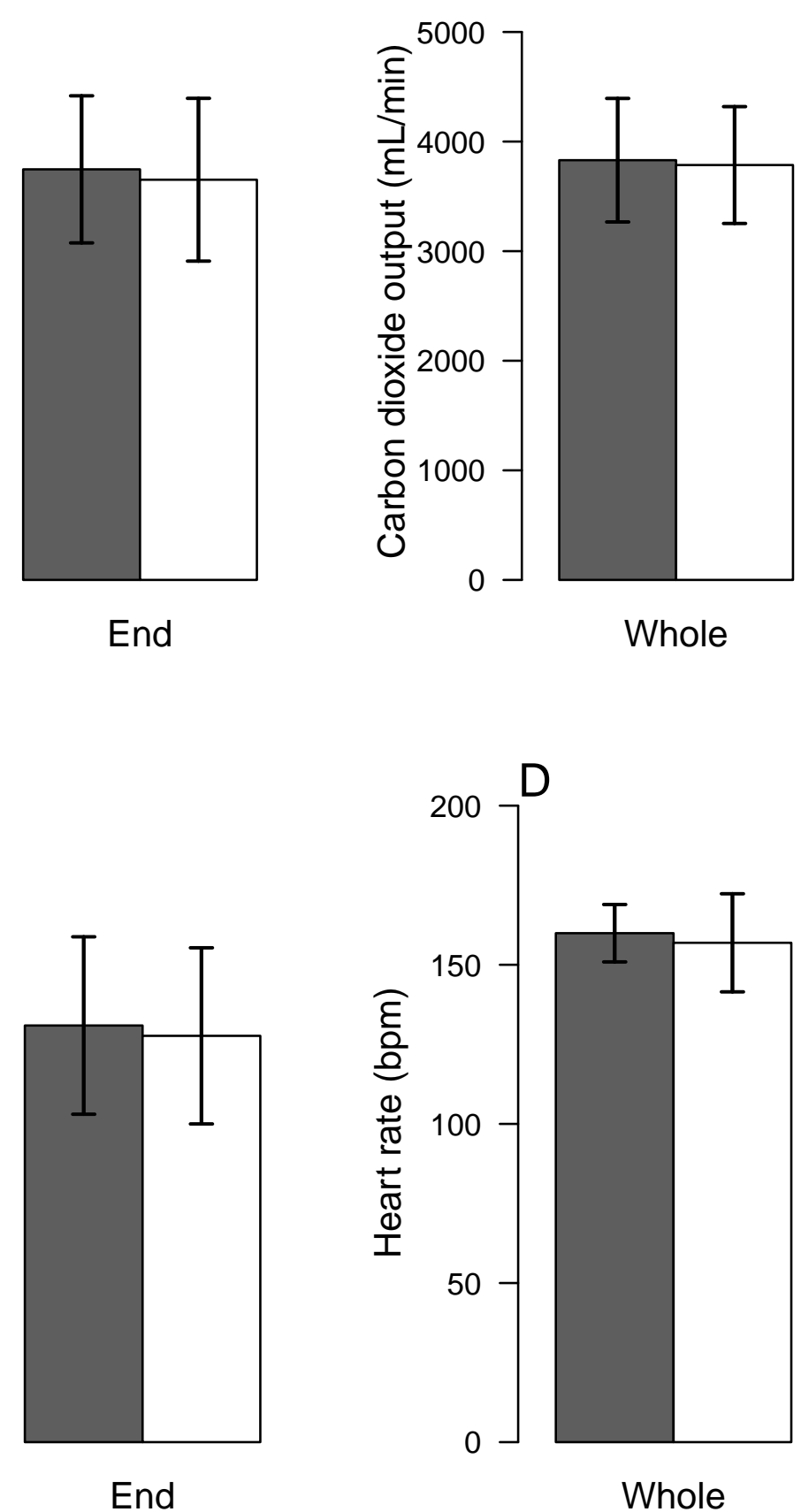

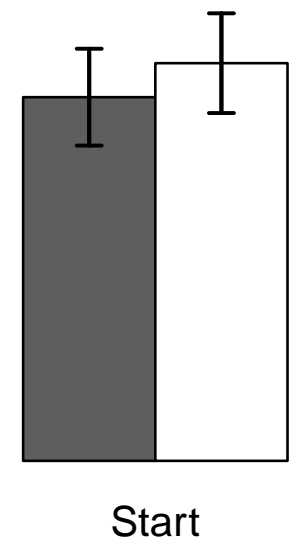

$\square$ BJ

$\square \mathrm{PL}$
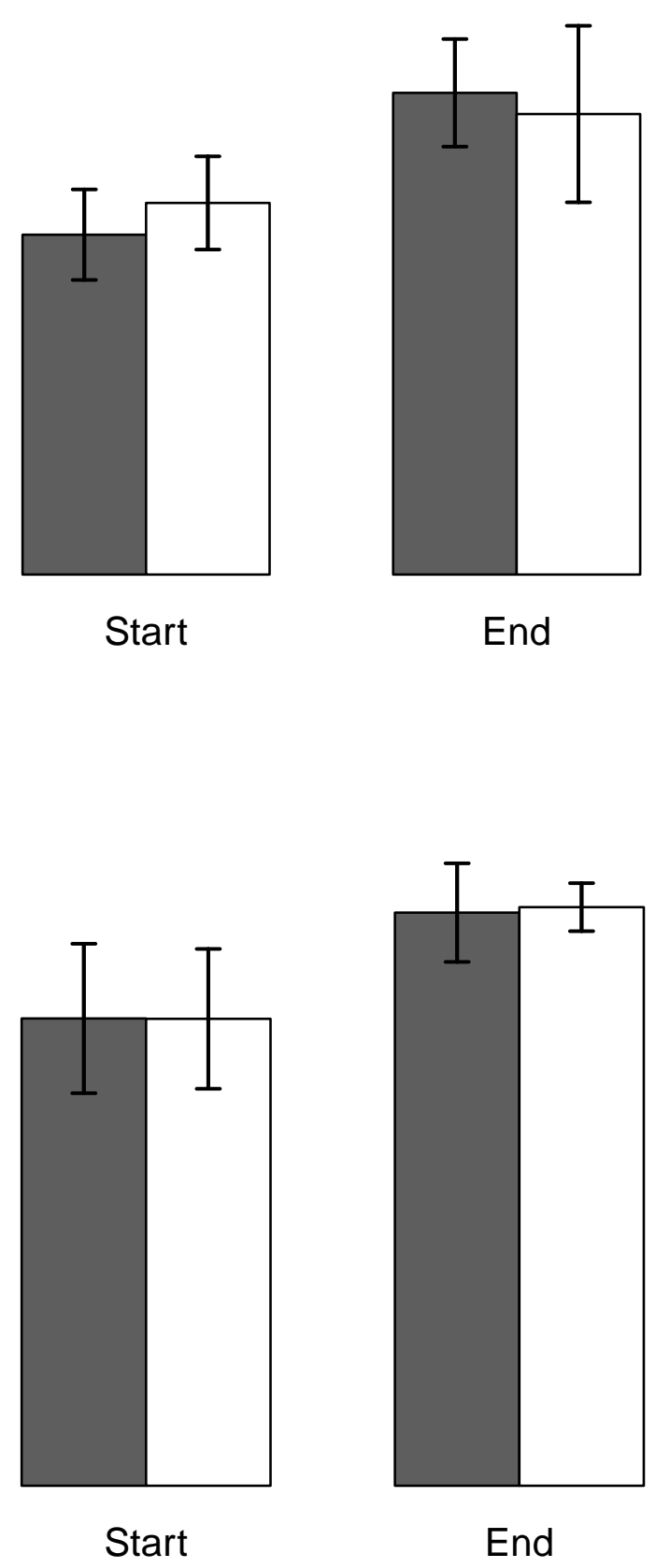